\title{
Artigo/Article
}

\section{Papilomavírus humano: prevalência e genótipos encontrados em mulheres HIV positivas e negativas, em um centro de referência no extremo Sul do Brasil}

\author{
Human papillomavirus: prevalence and genotypes found among HIV-positive and negative \\ women at a reference center in the far south of Brazil
}

\section{Ludmila Gonçalves Entiauspe ${ }^{1}$, Lisiane Ortiz Teixeira ${ }^{1}$, Raul Andrés Mendoza-Sassi ${ }^{2}$, Carla Vitola Gonçalves ${ }^{2,3}$, Paulo Gonçalves ${ }^{2,3}$ e Ana Maria Barral de Martinez ${ }^{1}$}

\section{RESUMO}

Introdução: $\mathrm{O}$ objetivo deste estudo foi detectar a presença do papilomavírus humano e verificar a prevalência e distribuição dos genótipos HPV-6, -11, -16 e -18 em mulheres HIV-1 positivas e negativas. Métodos: Analisou-se amostras de secreção cervical de 98 mulheres por reação em cadeia da polimerase nested para presença do HPV e tipo-específica para detecção dos genótipos, sendo estes confirmados por análise dos fragmentos de restrição. Realizou-se os testes do qui-quadrado e Fisher para a análise estatística. Resultados: O DNA-HPV foi observado em $66,3 \%$ das amostras analisadas, $76,4 \%$ no grupo HIV positivo e $60 \%$ no grupo HIV negativo $(\mathrm{p}=0,1)$. Uma prevalência maior de infecção viral por genótipos oncogênicos foi observada no grupo de pacientes HIV positivo $(65,2 \%)$ quando comparado ao grupo HIV negativo $(28,6 \%),(p=0,006)$, sendo HPV-16 foi o mais frequente nos dois grupos, seguido pelo HPV-18. Conclusões: Sugere-se que mulheres HIV positivas apresentam maior probabilidade de se infectar por genótipos oncogênicos de HPV, ressaltando a importância de um programa de rastreamento e diagnóstico diferenciado para este grupo.

Palavras-chaves: Papilomavírus humano. HIV. Câncer de colo uterino. Reação em cadeia da polimerase.

\begin{abstract}
Introduction: The aim of this study was detect the presence of human papillomavirus and investigate the prevalence and distribution of the HPV-6, 11, 16 and 18 genotypes among HIV-1 positive and negative women. Methods: Samples of cervical smears from 98 women were analyzed using the nested polymerase chain reaction for the presence of HPV and using the type-specific technique for genotype detection. Genotypes were confirmed by means of restriction fragment analysis. The chi-square and Fisher tests were performed for the statistical analysis. Results: HPV-DNA was observed in $66.3 \%$ of the samples analyzed: $76.4 \%$ in the HIV-positive group and $60 \%$ in the HIV-negative group $(\mathrm{p}=0.1)$. Higher prevalence of viral infection due to oncogenic genotypes was observed in the HIV-positive group (65.2\%) than in the HIV-negative group (28.6\%), ( $\mathrm{p}=0.006)$, and HPV-16 was the most frequent in the two groups, followed by HPV-18. Conclusions: It is suggested that HIV-positive women present a higher likelihood of infection by oncogenic HPV genotypes, and the importance of a screening and differential diagnosis program for this group is highlighted.
\end{abstract}

Key-words: Human papillomavirus. HIV. Cervical cancer. Polymerase chain reaction.

1. Laboratório de Biologia Molecular, Faculdade de Medicina, Universidade Federal do Rio Grande, Rio Grande, RS. 2. Departamento Materno Infantil, Faculdade de Medicina, Universidade Federal do Rio Grande, Rio Grande, RS. 3. Serviço de Ginecologia e Obstetrícia Hospital Universitário Dr. Miguel Corrêa Riêt Júnior, Rio Grande, RS.

Endereço para correspondência: M.Sc. Ludmila G. Entiauspe. Laboratório de Biologia MolecularFAMED/FURG. Rua General Osório, Centro, 96201-900 Rio Grande, RS.

Tel: 5553 9151-7849.

e-mail: ludmila.entiauspe@gmail.com

Recebido para publicação em 23/06/2009

Aceito em 05/04/2010

\section{INTRODUÇÃO}

Estudos epidemiológicos e moleculares têm mostrado a íntima relação entre o papilomavírus humano (HPV) e o surgimento de câncer cervical, bem como suas lesões precursoras, inferindo que a presença do vírus seja um agente causal para estas malignidades ${ }^{1}$. DNA do HPV tem sido detectado em até $99,7 \%$ dos cânceres cervicais em todo o mundo². Os HPVs são subdivididos em baixo e alto risco, de acordo com o seu potencial oncogênico ${ }^{3,4}$. Os HPVs de alto risco oncogênico estão frequentemente associados à lesão intraepitelial (SIL) de alto grau e neoplasias malignas do colo uterino ${ }^{5}$.

O Instituto Nacional do Câncer (INCA) estimou para os anos de 2008 e 2009 uma incidência de câncer de colo uterino no Brasil de 18.680, com um risco estimado de 19 casos a cada 100 mil mulheres. No Estado do Rio Grande do Sul, esta estimativa mostrou que 1.610 mulheres desenvolverão a doença, e uma incidência de 230 casos de câncer de colo de útero para capital do estado, Porto Alegre ${ }^{6}$.

Alguns autores acreditam que o estado de imunocompetência do hospedeiro possa ter relação com a evolução das lesões cervicais ${ }^{3,7,8}$. A capacidade do vírus persistir no hospedeiro pode ser aumentada por fatores que levam à supressão ou abolição da imunidade celular, como o uso de drogas citotóxicas em transplantados, imunodeficiências inatas ou adquiridas como a causada pelo vírus da imunodeficiência humana (HIV $)^{9,10}$. Estudos mostraram que mulheres HIV positivas apresentam chance 13,3 vezes maior de desenvolver neoplasias malignas no colo uterino, e que infecções pelo HPV e HIV são mais frequentes em mulheres no auge da capacidade produtiva e reprodutiva ${ }^{11,12}$.

Com base neste contexto, este estudo teve como objetivo detectar o HPV e identificar os genótipos mais frequentes através da reação em cadeia da polimerase (PCR) com confirmação por análise de 
fragmentos de restrição (RFLP) em grupos mulheres HIV positivas e negativas as quais buscavam atendimento no ambulatório de Infectologia e Planejamento Familiar do Serviço de Ginecologia e Obstetrícia do Hospital Universitário "Dr. Miguel Corrêa Riêt Jr" (HU-FURG).

\section{MÉTODOS}

\section{População do estudo}

Trata-se de um estudo do tipo transversal, realizado entre $2006 \mathrm{e}$ 2007. De 108 mulheres, selecionadas de forma sequencial, conforme as visitas ao ambulatório ginecológico de infectologia e planejamento familiar, 98 ( 38 HIV positivas e 60 HIV negativas) concordaram em participar do estudo. As participantes assinaram o Termo de Consentimento Livre e Esclarecido e foram encaminhadas à coleta em seus respectivos ambulatórios, onde coletou-se amostras de secreção cérvico-vaginal da região do endocérvice para as análises citológica e molecular. A análise citopatológica foi realizada como procedimento de rotina do Laboratório de Patologia da Universidade Federal do Rio Grande, e os resultados obtidos foram posteriormente comparados aos resultados da PCR. Foi considerado como critério de exclusão pacientes histerectomizadas.

\section{Coleta das amostras}

As amostras coletadas para a análise biomolecular foram acondicionadas em tubos criogênicos contendo $1 \mathrm{~mL}$ de tampão T.E. (10mM Tris- $\mathrm{HCl} \mathrm{pH} 8,5 ; 1 \mathrm{mM}$ EDTA) e encaminhadas ao Laboratório de Biologia Molecular da Faculdade de Medicina (FAMED) da FURG.

\section{Análise das amostras}

Para extração de DNA, uma alíquota de $100 \mu \mathrm{L}$ das amostras foi submetida à incubação a $95^{\circ} \mathrm{C}$ por 15 minutos em termo-bloco, seguido de centrifugação a $14.000 \mathrm{rpm}$ durante 10 minutos. $\mathrm{O}$ sobrenadante foi transferido a um novo tubo e ressuspendido em $100 \mu \mathrm{L}$ de tampão T.E. Para garantir a adequacidade do DNA extraído foi realizada a PCR para o gene humano CCR2, utilizando os primers descritos previamente por Magierowska e cols ${ }^{13}$.

A detecção do HPV foi realizada pela técnica de nested $\mathrm{PCR}^{14}$. No primeiro round, utilizaram-se os primers externos MY09/11, que amplificam uma sequência de $450 \mathrm{pb}$ da região L1 do HPV ${ }^{15}$. Para o segundo round, foram usados os primers internos GP5/6, amplificando um fragmento de $140 \mathrm{pb}^{16}$. Ambas as reações foram realizadas em um volume final de $50 \mu \mathrm{L}$, contendo $2,5 \mathrm{U}$ da enzima Taq DNA polimerase, primers na concentração de $50 \mathrm{ng} / \mu \mathrm{L}$ cada, 3,0mM de $\mathrm{MgCl}_{2}, 200 \mu \mathrm{M}$ de cada DNTP e $\mathrm{H}_{2} \mathrm{O}$ Mili-Q QSP, com desnaturação inicial de $95^{\circ} \mathrm{C}$ por 9 minutos e extensão final de $72^{\circ} \mathrm{C}$ por 5 minutos ${ }^{14,17}$. Para o primeiro round, utilizou-se $5 \mu \mathrm{L}$ de DNA extraído, e uma alíquota de $5 \mu \mathrm{L}$ do produto obtido deste para o segundo round. As condições da reação para o primeiro round foram constituídas por 40 ciclos subsequentes de $94^{\circ} \mathrm{C}$ por 30 segundos para desnaturação, $45^{\circ} \mathrm{C}$ por 30 segundos para o anelamento, $72^{\circ} \mathrm{C}$ por 30 segundos para extensão, e para o segundo round, 40 ciclos subsequentes de $95^{\circ} \mathrm{C}$ por 1 minuto, $55^{\circ} \mathrm{C}$ por 1 minuto, e $72^{\circ} \mathrm{C}$ por 1 minuto, para desnaturação, anelamento e extensão, respectivamente ${ }^{14}$. $\mathrm{O}$ amplicon foi visualizado em gel de agarose $1 \%$ e $2 \%$, respectivamente, para o primeiro e segundo round em transiluminador ultravioleta (UV). Como controle positivo da reação, foi usado um controle positivo (um fragmento de $450 \mathrm{pb}$ correspondente às células $\mathrm{SiHa}$ ) e um controle negativo com omissão de qualquer DNA. Utilizando como template as amostras de DNA genômico positivos para HPV, realizou-se a identificação dos genótipos pela PCR tipo-específica (PCR-TS), usando os pares de primers para HPV-6 e -11, e HPV-16 e - 18 já descritos ${ }^{14,18}$, os quais amplificam um fragmento de 280, 360, 253 e $201 \mathrm{pb}$, respectivamente. Juntamente foram usados controles positivos de linhagens de células $\mathrm{SiHa}$ (infectadas pelo HPV-16) e HeLa (infectadas pelo HPV-18). As condições de ciclagem, foram: 35 ciclos subsequentes com extensão de $94^{\circ} \mathrm{C}$ por 30 segundos, anelamento de $55^{\circ} \mathrm{C}\left(65^{\circ} \mathrm{C}\right.$ para o genótipo -11) durante 30 segundos, e extensão de $72^{\circ} \mathrm{C}$ por 1 minuto. Os produtos obtidos foram visualizados em gel de agarose $1,5 \%{ }^{14}$.

As amostras positivas para o DNA-HPV foram submetidas à técnica de RFLP para validar os genótipos identificados pela PCR$\mathrm{TS}^{19}$. Os primers utilizados na PCR foram mapeados sobre a região L1, e os locais de restrição então foram identificados dentro da região amplificada pelos primers MY09/11 utilizando o software VECTOR NTI $8.0^{\circ}$. Para garantir que os padrões de restrição seriam únicos, as sequências dos fragmentos de restrição foram comparadas aos genomas de HPV encontrados no NCBI-GenBank, usando o programa BLAST (http://blast.ncbi.nlm.nih.gov/Blast.cgi). Uma alíquota de $15 \mu \mathrm{L}$ dos amplicons gerados pela PCR MY09/11 foram digeridos com as enzimas de restrição EcoRI e BamHI. O padrão dos fragmentos obtidos foi analisado conforme reportado anteriormente por Bernard e cols e visualizados em gel de agarose 2,5\% ${ }^{19}$.

\section{Análise estatística}

O poder da amostra foi de $80 \%$ para encontrar uma diferença de $30 \%$, considerando um nível de confiança de $95 \%$ e uma prevalência de $80 \%$ HIV positivas e $50 \%$ HIV negativas. O desfecho medido foi a detecção de HPV pela técnica de PCR. Para as análises, utilizou-se o teste do qui-quadrado $\left(\chi^{2}\right)$ e/ ou o teste de Fisher considerando-se significativas aquelas variáveis que alcançaram um $\mathrm{p}<0,05$ no teste bicaudal.

\section{Ética}

Este estudo foi submetido e aprovado pelo Comitê de Ética em Pesquisa na Área da Saúde (CEPAS), da FURG em maio de 2007.

\section{RESULTADOS}

De um total de 108 pacientes, $10(9,3 \%)$ recusaram-se a participar do estudo. Das 98 pacientes restantes, 38 (38,8\%) eram portadoras do HIV-1 e $60(61,2 \%)$ eram HIV negativas. A média de idade das participantes foi de 34,8 (DP 12,6); idade mínima 14 anos e máxima 74 anos; $59,7 \%$ encontravam-se entre as séries iniciais do Ensino Fundamental, e 40,3\% das mulheres nas séries do Ensino Médio.

Com relação à citologia, 50\% das participantes do grupo HIV negativo apresentavam citologia normal, em $41,7 \%$ foi detectada inflamação; 4,2\% mostravam lesão escamosa intraepitelial de baixo grau (LSIL) e 4,2\% células escamosas atípicas de significado indeterminado (ASC-US). Entre as mulheres HIV positivas, 26,3\% apresentavam lesões escamosa intraepitelial de alto grau (HSIL), $23,7 \%$ citologia normal, $21,1 \%$ inflamação, $27,1 \%$ apresentavam LSIL e 7, 9\% ASC-US.

DNA-HPV foi encontrado em 66,3\% das amostras $\left(n^{\circ}=65 / 98\right)$ pela técnica de nPCR, sendo $36(60 \%)$ de pacientes HIV negativas e $29(76,3 \%)$ de pacientes HIV positivas. Quanto à genotipagem do 
HPV, observou-se DNA HPV-16 em nove (9,2\%), quatro (6,7\%) amostras, sendo HIV negativas e cinco $(13,2 \%)$ HIV positivas. HPV18 foi encontrado em três(3,1\%) amostras, das quais duas (5,3\%) eram pertencentes ao grupo HIV positivo e uma $(1,7 \%)$ ao HIV negativo (Tabela 1). Os genótipos de baixo risco HPV-6 e -11 não foram observados em nenhuma das amostras analisadas.

Em 53 amostras HPV positivas pela PCR-TS não foi possível identificar quais genótipos estavam presentes. Estas foram consideradas como genótipo indeterminado (HPV-X), sendo trinta (50\%) no grupo HIV negativo e vinte e três $(60,5 \%)$ no grupo HIV positivo. A Tabela 2 mostra que, excluindo-se a variável HPV-X, foi possível observar que nas 45 amostras restantes, $26,7 \%\left(n^{\circ}=12\right)$ eram genótipos de alto risco oncogênico e $46,7 \%$ deste resultado foi observado no grupo HIV positivo $(\mathrm{p}=0,032)$.

Comparando os resultados da PCR com o laudo citopatológico, DNA-HPV esteve presente em 54,5\% (nº 18/33) amostras com citologia normal, 67,9\% (no 19/28) com padrão inflamatório, 90\% (n⿳⺈⿴囗十一 10 ) dos casos com LSIL, e 100\% dos casos de HSIL (no10/10). Não foi detectado DNA-HPV em casos com diagnóstico de ASCUS (Tabela 3).
TABELA 1 - Prevalência de HPV e genótipos oncogênicos de acordo com o status HIV.

\begin{tabular}{|c|c|c|c|c|}
\hline \multirow{2}{*}{$\begin{array}{l}\text { Status } \text { HIV }^{a} \\
\text { no } 98^{c}\end{array}$} & \multicolumn{2}{|c|}{ Prevalência $\mathrm{HPV}^{b}\left(\mathrm{n}^{\circ}\right.$ 98) } & \multicolumn{2}{|c|}{ Prevalência HPV de alto risco } \\
\hline & $\%$ & $\mathrm{n}^{\mathrm{o}}$ & $\%$ & $\mathrm{n}^{\circ}$ \\
\hline Positivo $^{c}$ & 76,3 & $29 / 38^{d}$ & 46,7 & $7 / 15^{e}$ \\
\hline Negativo $^{c}$ & 60,0 & $36 / 60$ & 16,7 & $5 / 30$ \\
\hline Total & 66,3 & $65 / 98$ & 26,7 & $12 / 45$ \\
\hline
\end{tabular}

${ }^{a} \mathrm{HIV}$ : vírus da imunodeficiência humana, ${ }^{b} \mathrm{HPV}$ : papilomavírus humano, ${ }^{c} \mathrm{Grupo}$ HPV-X (genótipo indeterminado) excluso, Teste $\chi^{2}:{ }^{d} \mathrm{p}=0,1,{ }^{e} \mathrm{p}=0,032$.

TABELA 2 - Distribuição dos casos de acordo com a positividade para DNAHPV segundo os grupos estudados.

\begin{tabular}{|c|c|c|c|c|c|c|c|}
\hline \multirow[b]{2}{*}{ Genótipos } & \multicolumn{2}{|c|}{ Total } & \multicolumn{2}{|c|}{$\mathrm{HIV}^{a}{ }^{a}$} & \multicolumn{2}{|c|}{ HIV- } & \multirow[b]{2}{*}{$p$} \\
\hline & $\mathrm{n}^{\mathrm{o}}$ & $\%$ & $\mathrm{n}^{\mathrm{o}}$ & $\%$ & $\mathrm{n}^{\mathrm{o}}$ & $\%$ & \\
\hline HPV-16 & 9 & 9,2 & 5 & 13,2 & 4 & 6,7 & 0,08 \\
\hline HPV-18 & 3 & 3,0 & 2 & 5,3 & 1 & 1,7 & 0,617 \\
\hline HPV-X ${ }^{b}$ & 53 & 54,1 & 23 & 60,5 & 30 & 50,0 & 0,852 \\
\hline HPV negativo & 33 & 33,7 & 8 & 21,0 & 25 & 41,7 & 0,284 \\
\hline Total & 98 & 100,0 & 38 & 100,0 & 60 & 100,0 & \\
\hline
\end{tabular}

Teste do $\chi^{2}$, ${ }^{a} \mathrm{HIV}$ : vírus da imunodeficiência humana, ${ }^{b} \mathrm{HPV}-\mathrm{X}$ : papilomavírus humano detectado por PCR consenso, mas de genótipo indeterminado.

TABELA 3 - Presença do DNA-HPV em mulheres HIV positivas e negativas de acordo com o diagnóstico citopatológico.

\begin{tabular}{|c|c|c|c|c|c|c|c|c|c|c|c|c|}
\hline \multirow[b]{3}{*}{ HPV } & \multicolumn{10}{|c|}{ Citopatológico } & & \\
\hline & \multicolumn{2}{|c|}{ normal } & \multicolumn{2}{|c|}{ inflamatório } & \multicolumn{2}{|c|}{ LSIL } & \multicolumn{2}{|c|}{ HSIL } & \multicolumn{2}{|c|}{ ASC-US } & \multicolumn{2}{|c|}{ total } \\
\hline & no & $\%$ & $\mathrm{n}^{\mathrm{o}}$ & $\%$ & $\mathrm{n}^{\circ}$ & $\%$ & $\mathrm{n}^{\circ}$ & $\%$ & $\mathrm{n}^{\mathrm{o}}$ & $\%$ & $\mathrm{n}$ o & $\%$ \\
\hline Positivo & 18 & 54,5 & 19 & 67,9 & 9 & 90,0 & 10 & 100,0 & 0 & 0,0 & 56 & 65,1 \\
\hline Negativo & 15 & 45,5 & 9 & 32,1 & 1 & 10,0 & 0 & 0,0 & 5 & 100,0 & 30 & 34,9 \\
\hline Total & 33 & 100,0 & 28 & 100,0 & 10 & 100,0 & 10 & 100,0 & 5 & 100,0 & 86 & 100,0 \\
\hline
\end{tabular}

Teste do $\chi^{2}, p=0,001, H P V$ : papilomavírus humano, LSIL: lesão escamosa intraepitelial de baixo grau, HSIL: lesão escamosa intraepitelial de alto grau, ASC-US: células escamosas atípicas de significado indeterminado.

\section{DISCUSSÃO}

Nenhum outro estudo semelhante na região sul do Estado do Rio Grande do Sul (RS) foi encontrado, sendo este o primeiro a descrever o diagnóstico molecular do HPV e identificação dos seus genótipos. Em estudos similares realizados no estado, foi encontrada uma prevalência de HPV de 28,4\% na Cidade de Porto Alegre (CN Igansi: dados não publicados), e $13 \%$ na Grande Porto Alegre ${ }^{20}$. Especula-se que a frequência de HPV encontrada possa estar relacionada com o tipo população estudada e com o tipo de método de detecção utilizado.

Estudos realizados relataram uma maior prevalência para o genótipo HPV-16 tanto em mulheres HIV positivas quanto negativas ${ }^{7,8,21-23}$. Embora seja apontada uma variação quanto ao segundo genótipo mais prevalente, a maioria dos estudos relatou o HPV-18 como o mais presente. Em estudos no Sul do Brasil, observou-se que o genótipo HPV-16 foi o mais prevalente, seguido do HPV-18, dados estes que entram em consonância com esta pesquisa ${ }^{11}$. Tais observações sugerem que a implementação da vacina quadrivalente contra o HPV nesta região apresentaria resultados positivos com relação à prevenção do câncer de colo uterino mediado pelos genótipos HPV-16 e 18.

Em relação à citologia, o fato de ter sido detectado DNA-HPV em $54,5 \%$ das amostras com laudo citopatológico normal, possivelmente deve-se as seguintes questões: a) a alteração celular causada pelo HPV seja um fenômeno progressivo, e que devido ao tempo de infecção, possivelmente sua presença ainda não foi capaz de causar tais transformações detectáveis pelos métodos citopatológicos e anatomopatológicos convencionais, b) cerca de $10-20 \%$ das mulheres positivas para HPV apresentam alterações citológicas e c) a observação apropriada a partir de esfregaços irregulares e a pouca quantidade de células colocadas na lâmina (cerca de 20\%) contribuem para os resultados falso-negativos ocorridos na citologia de rotina ${ }^{21,24}$. Acredita-se que o percentual encontrado em amostras com LSIL negativas para HPV pela PCR possa estar relacionado ao fato que ao coletar o material citopatológico, o local escolhido para a coleta não contivesse um número suficiente de células infectadas ou apresentasse algum fator inibitório na reação ${ }^{21}$. Todas as lesões de alto grau estavam relacionadas à presença de HPV oncogênico, sendo que estes achados refletem a expectativa de que lesões de alto grau, consideradas pré-malignas estejam associadas à presença de HPV oncogênico, concordando com estudos anteriores ${ }^{4,5}$.

Neste estudo, foi observado que mulheres infectadas pelo HIV apresentaram uma tendência maior à infecção por genótipos oncogênicos de HPV com relação às soronegativas. Relatos na literatura mostram que a imunossupressão causada pelo HIV favorece a infecção por HPV de genótipos oncogênicos aumenta de forma significativa para a progressão em neoplasia intraepitelial cervical em mulheres HIV positivas ${ }^{22}$. No entanto, faz-se válido salientar que neste trabalho foram encontrados apenas os genótipos HPV-16 e -18, não sabendo-se portanto, se o grupo de genótipos indeterminados portava outros genótipos de HPV de baixo risco ou alto risco. 
Supõe-se que por não terem sidos detectados os genótipos HPV-6 e HPV-11, provavelmente devam-se ao fato das seguintes hipóteses: a) por não haver presença de verrugas anogenitais nas amostras coletadas, possivelmente as pacientes não apresentavam infecção para os HPV-6 e -11 ; b) estes genótipos não oncogênicos encontram-se na forma epissomal dentro do hospedeiro, portanto, talvez a técnica empregada para a extração de DNA não tenha sido a mais indicada para estes genótipos, ou c) considerando-se que a Cidade de Rio Grande é uma cidade com características epidemiológicas diferenciadas ${ }^{25}$, possa-se estar frente a um cenário onde surge a hipótese de que os genótipos de baixo risco oncogênicos possam também ser diferentes àqueles encontrados no restante do país. Sendo assim, não seria possível detectá-los pela técnica de PCR tipo-específica para estes dois genótipos. Os autores sugerem que a utilização da técnica de sequenciamento para genotipagem em trabalhos futuros possibilitará a obtenção um mapa mais completo dos genótipos prevalentes nesta região.

O presente trabalho apresentou limitações. Acredita-se que se não houvessem ocorrido perdas durante a coleta das amostras e o número amostral calculado consequentemente fosse maior, os dados possivelmente apresentariam maior poder estatístico. Além disso, por ser um estudo transversal, as associações encontradas não podem ser consideradas causais por não se obter o conhecimento sobre qual infecção ocorreu primeiramente (HIV ou HPV), pois os dados foram todos obtidos em um mesmo ponto no tempo. No entanto, por apresentar como objetivo a detecção do HPV e dos genótipos -6, -11,-16 e -18, este estudo foi teve seu propósito alcançado com a metodologia proposta.

Em conclusão, este estudo aponta uma elevada prevalência de genótipos oncogênicos de HPV em mulheres HIV positivas quando comparados ao grupo de mulheres HIV negativo. Espera-se que as técnicas de biologia molecular empregadas no estudo futuramente possam servir como ferramenta complementar ao diagnóstico de tríade citopatológica, permitindo assim uma detecção e tratamento precoces destas lesões, ressalvando a importância de um programa de rastreamento, diagnóstico e aconselhamento diferenciado nestas populações.

\section{AGRADECIMENTOS}

Ao Serviço de Ginecologia e Obstetrícia e às médicas patologistas do Laboratório de Patologia do do HU-FURG, pelo suporte e facilidades para o desenvolvimento deste trabalho.

\section{CONFLITO DE INTERESSE}

Os autores declaram não haver nenhum tipo de conflito de interesse no desenvolvimento do estudo.

\section{REFERÊNCIAS}

1. De Villiers EM, Fauquet C, Broker TR, Bernard HU, zur Hausen H. Classification of papillomaviruses. Virol 2004; 324:17-27.

2. Sellors JW, Karwalajtys TL, Kaczorowski J, Mahony JB, Lytwyn A, Chong S, et al. Incidence, clearance and predictors of human papillomavirus infection in women. CMAJ 2003; 168:421-425.

3. Cox JT. The development of cervical câncer and its precursors: what is the role of human papillomavirus infection? Cur Opin Obstet Gynecol 2006; 18(suppl 1): S5 - S13.

4. Muñoz N, Castellsagué X, de Gonzaléz AB, Gissman L. Chapter 1: HPV in the etiology of human cancer. Vaccine 2006; 24:S3/1-S3/10.
5. Muñoz N, Bosch FX, de Sanjose S, Herrero R, Castellsagué X, Shah KV, et al. Epidemiologic classification of human papillomavirus types associated with cervical cancer. N Engl J Med 2003; 348:518-527.

6. Brasil. Ministério da Saúde. Instituto Nacional do Câncer (INCA). Estimativas 2008: Incidência de Câncer no Brasil. Rio de Janeiro: INCA; 2007.p. 94.

7. Levi JE, Fernandes S, Tateno AF, Motta E, Lima LP, Eluf-Neto J, et al. Presence of multiple human papillomavirus types in cervical samples from HIV-infected women. Ginecol Oncol 2004; 92: 225-231.

8. Levi JE, Fink MCS, Canto CLM, Carretiero N, Matsubara R, Linhares I, et al Human Papillomavirus prevalence, viral load and cervical intraepithelial neoplasia in HIV-infected women. Braz J Infect Dis 2002; 6:129-134.

9. Dev D, Lo Y, Ho GYF, Burk RD, Klein ES. Incidence of and risk factors for genita human papillomavirus infection in women drug user. J AIDS 2006; 41: 527-529.

10. Sanjose S, Palefsky J. Cervical and anal HPV infections in HIV positive women and men. Virus Res 2002; 89:201-211.

11. Campos RR, Melo VH, Castilho DM Del, Nogueira CPF. Prevalência do papilomavírus humano e seus genótipos em mulheres portadoras e nãoportadoras do vírus da imunodeficiência humana. Rev Bras Ginecol Obst 2005; 27:248-256.

12. Nonnenmacher B, Breitenbach V, Villa LL, Prolla JC, Bozzetti MC. Identificação do papilomavírus humano por biologia molecular em mulheres assintomáticas. Rev Saude Publica 2002; 36: 95-100.

13. Magierowska M, Theodorou I, Debre P, Sanson F, Autran B, Rivière Y, et al Combined genotypes of CCR5, CCR2, SDF1, and HLA genes can predict the long-term nonprogressor status in human immunodeficiency virus-1-infected individuals. Blood J 1999; 93: 936-941.

14. Husnjak K, Grce M, Magdic L, Pavelic K. Comparison of five different polymerase chain reaction methods for detection of human papilomavírus in cervical cell specimens. J Virol Methods 2000;88:125-134.

15. Manos MM, Ting Y, Wright DK, Lewis AI, Broker TR, Wolinsky SM. The use of polymerase chain reaction amplification for the detection of genital human papillomaviruses. Cancer Cells 1989;7:209-214.

16. Sjniders PJF, van den Brule AJC, Schrijnemakers HFJ, Snow G, Meijer CJLM, Walboomers MM. The use of general primers in the polymerase chain reaction permits the detection of a broad spectrum of human papillomavirus genotypes. J Gen Virol 1990;71:173-181.

17. Gravitt PE, Peyton CL, Alessi TQ, Wheeler CM, Coutlée F, Hildesheim A et al. Improved amplification of genital human papillomaviruses. J Clin Microbiol 2000; 38: 357-361.

18. Chan MKM, Lau KM, Tsui Y, Wong FWS, Huang DP. Human Papillomavirus Infection in Hong Kong Chinese Women with Normal and Abnormal Cervix Detection by Polymerase Chain Reaction Method on Cervical Scrapes. Gynecol Oncol 1996; 60:217-223

19. Bernard HU, Chan SY, Manos MM, Ong CK, Villa LL, Delius H, Peyton DL, Bauer HM, Wheller CM. Identification and assessment of known and novel human papillomaviruses by polymerase chain reaction amplification, restriction fragment length polymorphisms, nucleotide sequence and phylogenetic algorithms. J Infect Dis 1994;170:1077-1085.

20. Nonnenmacher B, Pintos J, Bozzetti MC. Epidemiologic correlates of antibody response to human papillomavirus among women at low risk of cervical cancer. Int J STD AIDS 2003;14:258-265

21. Fernandes APM, Gonçalves MAG, Simões RT, Quintana SM, Duarte G, Donadi EA. Influência da infecção pelo HIV-1 sobre a presença do HPV em lesões do colo uterino. J Bras Doenças Sex Transm 2004;16:21-25.

22. Silverberg MJ, Schneider MF, Silver B, Anastos KM, Burk RD, Minkoff H, et al Serological Detection of Human Papillomavirus Type 16 Infection in Human Immunodeficiency Virus (HIV)-Positive and High-Risk HIV-Negative Women. Clin Vac Immunol 2006; 13:511-519.

23. Clifford G, Franceschi S, Diaz M, Muñoz N, Villa LL. Chapter 3: HPV typedistribution in women with and without cervical neoplastic diseases. Vaccine 2006; 24S3:S3/26-S3/34.

24. Wolschick NM, Consolaro MEL, Suzuki LE, Boer CG de. Câncer do colo do útero: tecnologias emergentes no diagnóstico, tratamento e prevenção da doença. Rev. Bras Anal Clin 2007; 39: 123-129.

25. Soares EAJM, Martínez AMB, Souza TM, Santos AFA, Hora V da, Silveira J, et al HIV-1 subtype C dissemination in southern Brazil. AIDS 2005; 19:S81-S86. 